\title{
OSAHS
}

\section{Risk factors for otitis media with effusion in children with adenoid hypertrophy}

\author{
Fattori di rischio per l'otite media effusiva nei bambini con ipertrofia adenoidea \\ Murat Songu¹, Akif Islek¹, Abdulkadir Imre², Hale Aslan², Ibrahim Aladag², Ercan Pinar², Semih Oncel² \\ ${ }^{1}$ Department of Otorhinolaryngology, Izmir Katip Celebi University, Ataturk Training and Research Hospital, Izmir, Turkey; \\ ${ }^{2}$ Department of Otorhinolaryngology, Izmir Katip Celebi University Medical Faculty, Izmir, Turkey
}

\begin{abstract}
SUMMARY
The aim of this study was to determine the most important risk factors in the development of otitis media with effusion (OME) in children with adenoid hypertrophy. A total of 539 patients undergoing surgery for adenoid hypertrophy (AH Group) $(n=429)$ or adenoid hypertrophy and otitis media with effusion $(\mathrm{AH}+\mathrm{OME}$ Group $)(\mathrm{n}=110)$ between February 2012 and February 2018 constituted the study group. Data were obtained on neonatal history (breastfeeding, bottle feeding), past health and medical history (presence of atopy or allergic rhinitis, snoring at night, cough, tonsillitis in the past 12 months), environmental factors (presence of pets, attending to daycare centers, district of school), family history (passive smoking at home, number of siblings, family size, parental education), and family income. The groups did not differ from each other for age $(\mathrm{p}=0.684)$ and gender $(p=0.728)$. Our data support the presence of atopy or allergic rhinitis $(p<0.001)$, frequent $(>5)$ tonsillitis $(p<0.001)$, attending to daycare centers $(p<0.001)$, exposure to smoke ( $\mathrm{p}<0.001)$, having 3 or more siblings $(\mathrm{p}<0.001)$, and 4 or more people in the household $(\mathrm{p}<0.001)$ as the main risk factors for OME. Comprehensive knowledge of modifiable risk factors found in this study could help to minimise the complications of OME in children.
\end{abstract}

KEY WORDS: otitis media with effusion, predictors, risk factors

\section{RIASSUNTO}

Lo scopo di questo studio è determinare i fattori di rischio più importanti per l'otite media effusiva (OME) nei bambini con ipertrofia adenoidea. 539 pazienti sono stati sottoposti a chirurgia per ipertrofia adenoidea o ipertrofia adenoidea + OME, fra febbraio 2012 e febbraio 2018. Sono stati valutati i dati circa la storia clinica neonatale e l'anamnesi remota, fattori ambientali, anamnesi familiare e lo status economico familiare. I gruppi sono risultati omogenei per età e genere. Dai nostri dati si evince che i fattori di rischio per l'OME sono la presenza di rinite allergicalatopica, tonsilliti ricorrenti, frequentazione dell'asilo nido, esposizione al fumo passivo, la presenza di 3 o più fratelli, la presenza di 4 o più persone conviventi. La correzione di tali fattori di rischio modificabili potrebbe contribuire a diminuire le complicanze dell'OME nei bambini.

PAROLE CHIAVE: otite media effusiva, fattori di rischio, fattori predittivi

\section{Introduction}

Otitis media with effusion (OME) is defined as the accumulation of fluid behind the intact tympanic membrane without signs and symptoms of acute ear infection ${ }^{1}$. Fluid in the middle ear affect the function of the tympanic membrane and middle ear and leads to conductive hearing loss, feeling of fullness in the ear and pain due to alterations in pressure ${ }^{2}$. OME is a prevalent disease that is encountered in childhood and may often be overlooked because its symptoms are not always severe. It is the most frequent cause of acquired hearing loss in preschool children ${ }^{2}$. Hearing loss that develops in early childhood may cause irreversible sequelae that
Received: November 15, 2018

Accepted: April 21, 2019

Correspondence

Murat Songu

Department of Otorhinolaryngology, Izmir Katip Celebi University, Ataturk Training and Research Hospital, Izmir, Turkey

Tel. +90 2322444444. Fax +90 2322431530

E-mail: songumurat@yahoo.com

Funding

None.

Conflict of interest

The Authors declare no conflict of interest.

How to cite this article: Songu M, Islek A, Imre A, et al. Risk factors for otitis media with effusion in children with adenoid hypertrophy. Acta Otorhinolaryngol Ital 2020;40:133-137. https:// doi.org/10.14639/0392-100X-2456

(C) Società Italiana di Otorinolaringoiatria e Chirurgia Cervico-Facciale

\section{(c) (1) () $)$}

This is an open access article distributed in accordance with the CC-BY-NC-ND (Creative Commons Attribution-NonCommercial-NoDerivatives 4.0 International) license. The article can be used by giving appropriate credit and mentioning the license, but only for non-commercial purposes and only in the original version. For further information: https:// creativecommons.org/licenses/by-nc-nd/4.0/deed.en 
may be lifelong, affecting the child's speech, language and social relations. In one study, it was found that $90 \%$ of children had at least one episode up to the age of $10^{3}$. Ninety percent of cases with otitis media with effusion spontaneously resolve within three months ${ }^{3}$. Between $5 \%$ and $10 \%$ of attacks may last more than one year. Thirty to $40 \%$ of children experience recurrent episodes ${ }^{4}$.

Numerous research has been performed to reveal the aetiology of OME ${ }^{4}$. Respiratory tract infections, adenoid hypertrophy, craniofacial malformations, mechanical obstruction of the nasopharynx, allergy and immunological factors have been suggested as the major aetiological factors in the pathogenesis of otitis media with effusion ${ }^{4}$. As additional factors in OME, race, gender, climatic conditions, environment, humidity, socioeconomic status, duration of breastfeeding, living in a crowded home, going to nursery or kindergarten, passive smoking and gastro-oesophageal reflux have all been suggested as possible factors ${ }^{5}$.

The effects of adenoid tissue on the formation of otitis media with effusion are due to supranormal size, disruption of the nasopharyngeal ventilation, obstruction of the Eustachian with a mass effect, accumulation of secretion, a source of infection, oedema due to inflammation and release of allergic inflammatory mediators from adenoid mast cells ${ }^{6}$. In our opinion, one of the most important limitations of screening studies aiming to reveal OME risk factors is the presence of unidentified adenoid tissue during examination. Considering this, we used adenoid hypertrophy as a common factor in both groups. In this way, we aimed to minimise the effect of adenoid hypertrophy on OME formation.

Despite being a very common disease in children, the literature regarding risk factors for OME in Turkish children is lacking, and risk factors in the English literature may be culturally and/or environmentally biased. The present study aimed to determine the most important risk factors in the development of OME in children with adenoid hypertrophy.

\section{Materials and methods}

\section{Study design}

The study was conducted in accordance with the principles of the Helsinki Declaration and approved by the local Institutional Review Board. A total of 539 patients undergoing surgery for adenoid hypertrophy (AH Group) or adenoid hypertrophy and otitis media with effusion $(\mathrm{AH}+\mathrm{OME}$ Group) in the Department of Otorhinolaryngology at our university, between February 2012 and February 2018, constituted the study group. Patients were divided into two groups: those with AH only (AH Group) $(n=429)$ and those with AH and OME (AH + OME Group) ( $\mathrm{n}=110)$.
A diagnosis of OME was made with history, otoscopic findings, conduction-type hearing loss in audiometry and flat tympanograms. Effusion was also confirmed during surgery. Breast-fed children were defined as those who had received breast milk for at least six months after birth.

Exclusion criteria: Children with a chronic infection requiring prophylactic antibiotic therapy, craniofacial abnormalities, or immunodeficiency syndromes and children with ventilation tubes at the time of screening. Children with adhesive otitis were also excluded from the study.

\section{Outcome parameters}

The data obtained from patient records for estimation of potential risk factors for OME were neonatal history (breastfeeding, bottle feeding), past health and medical history (presence of atopy or allergic rhinitis, snoring at night, cough, tonsillitis in the past 12 months), environmental factors (presence of pets, attending to daycare centers, district of school), family history (passive smoking at home, number of siblings, family size, parental education) and socioeconomic background (income of the family).

\section{Statistical analysis}

Data were analysed using the IBM Statistical Package for Social Sciences v21 (SPSS Inc., Chicago, IL, USA). A normal distribution of the quantitative data was checked using the Kolmogorov-Smirnov test. Parametric tests (Independentsamples t-test and posthoc Tukey test) were applied to data of normal distribution, and non-parametric tests (MannWhiney U-test and Kruskal-Wallis Test) were applied to data of questionably normal distribution. Continuous data were presented as mean \pm standard deviation or median (minimummaximum), as appropriate. All differences associated with a $\mathrm{P}$ value $£ 0.05$ were considered statistically significant.

\section{Results}

Of the 539 patients (286 males, 253 females) whose charts were reviewed, the mean age was $7.02 \pm 3.86$ (range 2 to 14) years. The AH Group included 429 patients ( 225 males, 204 females) with a mean age of $7.34 \pm 3.49$ years; the AH+OME Group included 110 patients (61 males, 49 females) with a mean age of $6.91 \pm 4.02$ years. Groups did not differ considering age and gender $(\mathrm{p}=0.684$, and $\mathrm{p}=0.728$, respectively).

As for information on neonatal history, the results of the present study did not reveal a significant correlation between OME and breastfeeding $(\mathrm{p}=0.446)$ or bottle feeding $(\mathrm{p}=0.284)$ (Tab. I).

Regarding the past health and medical history, the prevalence of atopy or allergic rhinitis was $34 \%$ in patients 
Table I. Comparison of groups for factors influencing development of otitis media.

\begin{tabular}{|c|c|c|c|c|}
\hline Factors & & $\begin{array}{l}\text { AH Group }(n=429) \\
n(\%)\end{array}$ & $\begin{array}{c}\text { AH + OME Group }(n=110) \\
n(\%)\end{array}$ & $P$ value \\
\hline \multirow[t]{2}{*}{ Breastfeeding } & Yes & $373(87 \%)$ & $97(88 \%)$ & 0.446 \\
\hline & No & $56(13 \%)$ & $13(12 \%)$ & \\
\hline \multirow[t]{2}{*}{ Bottle feeding } & Yes & $193(45 \%)$ & $53(48 \%)$ & 0.284 \\
\hline & No & $236(55 \%)$ & $57(52 \%)$ & \\
\hline \multirow[t]{2}{*}{ Presence of atopy, or allergic rhinitis } & Yes & $107(25 \%)$ & $37(34 \%)$ & $<0.001$ \\
\hline & No & $322(75 \%)$ & $73(66 \%)$ & \\
\hline \multirow[t]{2}{*}{ Snoring at night } & Yes & $395(92 \%)$ & 98 (89\%) & 0.645 \\
\hline & No & $34(8 \%)$ & $12(11 \%)$ & \\
\hline \multirow[t]{2}{*}{ Cough } & Yes & $163(38 \%)$ & $46(42 \%)$ & 0.244 \\
\hline & No & $266(62 \%)$ & 64 (58\%) & \\
\hline \multirow[t]{2}{*}{ Frequent tonsillitis $(>5$ ) in the past 12 months } & Yes & $167(39 \%)$ & $70(64 \%)$ & $<0.001$ \\
\hline & No & $262(61 \%)$ & $40(36 \%)$ & \\
\hline \multirow[t]{2}{*}{ Presence of pets } & Yes & $51(12 \%)$ & $15(14 \%)$ & 0.446 \\
\hline & No & $378(88 \%)$ & $95(86 \%)$ & \\
\hline \multirow[t]{2}{*}{ Attending to daycare centers } & Yes & $180(42 \%)$ & $75(68 \%)$ & $<0.001$ \\
\hline & No & $249(58 \%)$ & $35(32 \%)$ & \\
\hline \multirow[t]{2}{*}{ District of school } & Low socioeconomic level & $292(68 \%)$ & 79 (72\%) & 0.368 \\
\hline & High socioeconomic level & $137(32 \%)$ & $31(28 \%)$ & \\
\hline \multirow{2}{*}{$\begin{array}{l}\text { Passive smoking at home (tobacco smoke } \\
\text { exposure) }\end{array}$} & Yes & $189(44 \%)$ & $62(56 \%)$ & $<0.001$ \\
\hline & No & $240(56 \%)$ & $48(4 \%)$ & \\
\hline \multirow[t]{2}{*}{ Number of siblings } & 2 or less & $197(46 \%)$ & $26(24 \%)$ & $<0.001$ \\
\hline & 3 or more & 232 (54\%) & $84(76 \%)$ & \\
\hline \multirow{2}{*}{ Family size (number of people in the household) } & 3 or less & $176(41 \%)$ & $31(28 \%)$ & $<0.001$ \\
\hline & 4 or more & $253(59 \%)$ & $79(72 \%)$ & \\
\hline \multirow[t]{2}{*}{ Parental education } & Well educated & $103(24 \%)$ & $24(22 \%)$ & 0.258 \\
\hline & Poor educated & $326(76 \%)$ & $86(78 \%)$ & \\
\hline \multirow[t]{2}{*}{ Family income } & Less than $500 \$ / m 0$ & $150(42 \%)$ & 42 (38\%) & 0.284 \\
\hline & More than $500 \$ / m 0$ & $249(58 \%)$ & $68(62 \%)$ & \\
\hline
\end{tabular}

AH: adenoid hypertrophy; OME: otitis media with effusion.

with OME, and $25 \%$ in those without OME ( $<<0.001)$. There was no difference between groups regarding snoring at night $(\mathrm{p}=0.645)$ and cough $(\mathrm{p}=0.244)$. The presence of frequent tonsillitis $(>5)$ in the past 12 months increased the prevalence of OME (64\% versus $39 \%)$, with a significant difference between groups $(\mathrm{p}<0.001)$.

We also evaluated the association of OME with environmental factors. Attending daycare centers was significantly more common among children with OME $(\mathrm{p}<0.001)$. No difference between groups was found according to the presence of pets $(\mathrm{p}=0.446)$ or school district (low vs. high socioeconomic level) $(\mathrm{p}=0.368)$.

As for family history, passive smoking at home was found to be a significant risk factor $(\mathrm{p}<0.001)$. OME was significantly more common among children with parents smoking in the home. Tobacco smoke exposure was revealed in $56 \%$ of children with OME, and in $44 \%$ of children without OME.
Number of siblings was found to be an important predictor of OME ( $<<0.001$ ); having 3 or more siblings was revealed in $76 \%$ of children with OME, and in $54 \%$ of children without OME. There was a statistically significant influence of family size on OME. Living with more than 4 persons in the household was seen in $72 \%$ of children with OME, while in $59 \%$ of children without OME $(\mathrm{p}<0.001)$. There was no difference between groups regarding parental education $(\mathrm{p}=0.258)$, and family income $(\mathrm{p}=0.284)$.

\section{Discussion}

The Panel Report from the "Ninth International Research Conference on Otitis Media" suggests that the aetiology of OME is multifactorial and that many different factors are implicated in the pathophysiology of this disease. ${ }^{7}$ However, although frequently studied, the influence of various factors 
on the pathogenesis of OME has remained controversial when results of previous studies are compared, and further investigation is thus warranted. In the present study, we found that the presence of atopy or allergic rhinitis, frequent $(>5)$ tonsillitis, attending daycare centres, exposure to smoke, having 3 or more siblings and 4 or more people in the household were the main risk factors for OME.

While $80 \%$ of children experience at least one OME attack within the first 10 years of their lifetime, OME is most commonly observed in children aged between six months and four years ${ }^{8}$. Many cases of OME spontaneously resolve within three months, but $30-40 \%$ of children have recurrent episodes and $5-10 \%$ of cases last more than one year ${ }^{9}$. Although not a very significant factor, OME is rare in children younger than one year of age and its incidence decreases significantly in patients over 10 years of age ${ }^{8}$. Our cases were most frequently observed in this age group. There is yet no consensus on the relationship between gender and OME. It is expected that the disease is more common in boys as mastoid pneumatization is more rapid in girls and boys experience upper respiratory infection (URI) episodes more frequently. There are also studies in the literature showing that OME is more common in males ${ }^{10}$. On the contrary, there are studies showing that there is no relationship between gender and the prevalence of $\mathrm{OME}^{11}$, and our result is consistent with these studies.

Several studies have confirmed the weak protective effects of breastfeeding or the increased risk of bottle feeding in OME. In two studies on the interaction of breastfeeding with weaning and infection ${ }^{12,13}$, the first OME episode occurred significantly earlier in children weaned before six months of age. A number of studies including ours on OME did not find breastfeeding as a significant factor.

Among the predisposing factors of OME, allergy is an important characteristic. In addition to many publications showing that OME is associated with allergy, there are also studies in which no relationship was established ${ }^{14}$. Allergies may predispose to OME by causing oedema around the Eustachian tube or primary mucosal disease in the middle ear. In the study of Aydoğan et al., $44.6 \%$ of children with OME had a food allergy, and allergy was suggested to be possibly effective either by nasal congestion or by determining the middle ear mucosa as a direct target organ ${ }^{15}$. In a study by Alles et al. in children aged 3 to 8 years with chronic or recurrent OME, and allergy symptoms of $89 \%$ of subjects were confirmed during examinations ${ }^{16}$. In a study by Martinez et al., skin tests of children with OME were found to be negative in $37.1 \%$ and positive in $62.9 \%$ of cases ${ }^{14}$. In addition, in the study published by Marseglia et al. the authors reported in 2008 that allergic rhinitis and adenoiditis were important risk factors for the development of OME and that the risk increased even further in the co-presence of both conditions ${ }^{17}$. In our study, we found a significantly higher association between allergic rhinitis and OME. Bergroth et al. highlighted that pet contacts during infancy may have a protective effect on respiratory tract symptoms and infections ${ }^{18}$. However, we did not observe any relationship between OME episodes and children who lived with pets.

Nasal and nasopharyngeal pathologies may contribute to the formation of OME by affecting the upper airway ${ }^{19}$. Sinusitis, septal curvature, hypertrophy of concha choanal atresia, or stenosis can all affect air passage through the nasopharynx. Nasopharyngeal malignancies may cause the development of effusion. Cases with inadequate pneumatisation constitute a risk factor in cases of tubal dysfunction. In our study, night snoring and cough were not risk factors for OME. As a result of our analysis, the incidence of acute tonsillitis in the last 12 months was found to be a significant factor for OME. Middle ear effusion is 6-7 times more frequent in the two to six-year-old group $^{20}$. Viral infections impair tubal function, and inadequate treatment of acute otitis may result in chronic effusion.

The results of studies investigating the relationship between smoking and frequency of OME are varied. In some studies, there is no association between smoking and frequency of OME, but other studies have reported that smoking increases the frequency of $\mathrm{OME}^{21}$. Kitchens et al. reported that children in whom a ventilation tube was applied for chronic OME were more frequently exposed to smoking than a control group. According to this, the number of smokers and the number of cigarettes smoked are important, in addition to passive smoke in the home ${ }^{22}$. In our study, exposure to passive cigarette smoke and OME were significantly associated.

Our findings showed that family size was also associated with a higher percentage of OME and that living with more than 4 persons in the household was seen in $72 \%$ of children with OME, compared to 59\% of children without OME. The presence of older siblings and day care attendance were both independent risk factors for OME in this population. These variables have previously been reported as predisposing to OME and are typically attributed to the increased chance of acquiring pathogens involved in OME or URIs from contact with siblings or other children ${ }^{14,23}$.

According to Daly et al. ${ }^{24}$, who studied maternal knowledge and practices regarding risk factors for otitis media among mothers in Minnesota, U.S. they found that lower levels of education were associated with poorer knowledge regarding otitis media, we suggest that health education regarding OME and its risk factors should be implemented from caregivers to address these lacunae especially to these illiterate conditions. The relationship between OME and socio-economic status is not clear. There are several publications claiming that the prevalence of OME is higher in communities with higher socioeconomic level, while others have advocated the 
contrary ${ }^{21,25}$. According to these authors, URIs are more frequently seen in societies with low socioeconomic level due to poor hygiene and other reasons. Therefore, it is believed that the prevalence of OME increases in societies with low socioeconomic level. In our study, we found that the socioeconomic level did not have a significant relationship with the prevalence of OME.

The main limitation of our study was its retrospective design. In addition, some details of history and factors that may influence outcomes may not be completely documented. Third, this was a single-institution study, and some caution should be taken before generalising our findings to other settings. Finally, the role and the importance of naso-pharyngeal microbiota was not considered due to the retrospective nature of the study. Many papers have been published in the last years about this topic, leading to a surprising new vision in the physiopathology of the nose and eustachian tube ${ }^{26}$. Due to these restrictions, any associations should be interpreted with caution.

This paper contributes to the understanding of the role of different risk factors in the development of OME among children. Specifically, our data support the presence of atopy or allergic rhinitis, frequent $(>5)$ tonsillitis, attending to daycare centres, exposure to smoke, having 3 or more siblings and 4 or more people in the household as main risk factors for OME. Comprehensive knowledge of modifiable risk factors found in this study could help to minimise the complications of OME in children.

\section{References}

1 Atkinson H, Wallis S, Coatesworth AP. Otitis media with effusion. Postgrad Med 2015;127:381-5. https://doi.org/10.1080/00325481.201 5.1028317

2 Harmes KM, Blackwood RA, Burrows HL, et al. Otitis media: diagnosis and treatment. Am Fam Physician 2013;88:435-40.

3 Cai T, McPherson B. Hearing loss in children with otitis media with effusion: a systematic review. Int J Audiol 2017;56:65-76. https://doi. org/10.1080/14992027.2016.1250960

4 Rosenfeld RM, Shin JJ, Schwartz SR, et al. Clinical practice guideline: otitis media with effusion (update). Otolaryngol Head Neck Surg 2016;154(1 Suppl):S1-41. https://doi. org/10.1177/0194599815623467

5 Eliçora SŞ, Öztürk M, Sevinç R, et al. Risk factors for otitis media effusion in children who have adenoid hypertrophia. Int J Pediatr Otorhinolaryngol 2015;79:374-7. https://doi.org/10.1016/j.ijporl.2014.12.030

6 Davcheva-Chakar M, Kaftandzhieva A, Zafirovska B. Adenoid vegetations - reservoir of bacteria for chronic otitis media with effusion and chronic rhinosinusitis. Pril (Makedon Akad Nauk Umet Odd Med Nauki) 2015;36:71-6. https://doi.org/10.1515/prilozi-2015-0080

7 Daly KA, Hoffman HJ, Kvaerner KJ, et al. Epidemiology, natural history, and risk factors: panel report from the Ninth International Research Conference on Otitis Media. Int J Pediatr Otorhinolaryngol 2010;74:231-40. https://doi.org/10.1016/j.ijporl.2009.09.006

8 Walker RE, Bartley J, Flint D, et al. Determinants of chronic otitis media with effusion in preschool children: a case-control study. BMC Pediatr 2017;17:4. https://doi.org/10.1186/s12887-016-0767-7
9 Casselbrant ML, Mandel EM, Doyle WJ. Information on co-morbidities collected by history is useful for assigning Otitis Media risk to children. Int J Pediatr Otorhinolaryngol 2016;85:136-40. https://doi. org/10.1016/j.ijporl.2016.03.040

10 Ungkanont K, Charuluxananan S, Komoltri C. Association of otoscopic findings and hearing level in pediatric patients with otitis media with effusion. Int J Pediatr Otorhinolaryngol 2010;74:1063-6. https://doi.org/10.1016/j.ijporl.2010.06.006

11 Gultekin E, Develioğlu ON, Yener M, et al. Prevalence and risk factors for persistent otitis media with effusion in primary school children in Istanbul, Turkey. Auris Nasus Larynx 2010;37:145-9. https:// doi.org/10.1016/j.anl.2009.05.002

12 Aniansson G, Alm B, Andersson B, et al. A prospective cohort study on breast-feeding and otitis media in Swedish infants. Pediatr Infect Dis J 1994;13:183-8. https://doi.org/10.1097/00006454-19940300000003

13 Duffy LC, Faden H, Wasielewski R, et al. Exclusive breastfeeding protects against bacterial colonization and day care exposure to otitis media. Pediatrics 1997;100:E7. https://doi.org/10.1542/peds.100.4.e7

14 Martines F, Bentivegna D, Di Piazza F, et al. The point prevalence of otitis media with effusion among primary school children in Western Sicily. Eur Arch Otorhinolaryngol 2010;267:709-14. https://doi. org/10.1007/s00405-009-1131-4

15 Aydogan B, Kiroglu M, Altintas D, et al. The role of food allergy in otitis media with effusion. Otolaryngol Head Neck Surg 2004;130:74750. https://doi.org/10.1016/j.otohns.2004.02.003

16 Alles R, Parikh A, Hawk L, et al. The prevalence of atopic disorder in children with chronic otitis media effusion. Pediatr Allergy Immunol 2001;12:102-6. https://doi.org/10.1046/j.0905-6157.2000.00008.x

17 Marseglia GL, Pagella F, Caimmi D, et al. Increased risk of otitis media with effusion in allergic children presenting with adenoiditis. Otolaryngol Head Neck Surg 2008;138:572-5. https://doi.org/10.1016/j. otohns.2008.01.020

18 Bergroth E, Remes S, Pekkanen J, et al. Respiratory tract illnesses during the first year of life: effect of dog and cat contacts. Pediatrics 2012;130:211-20. https://doi.org/10.1542/peds.2011-2825

19 Yazıcı H. Nasal mucociliary clearance in adenoid hypertrophy and otitis media with effusion. Curr Allergy Asthma Rep 2015;15:74. https://doi.org/10.1007/s11882-015-0576-3

20 Walker RE, Bartley J, Flint D, et al. Determinants of chronic otitis media with effusion in preschool children: a case-control study. BMC Pediatr 2017;17:4. https://doi.org/10.1186/s12887-016-0767-7

21 Saim A, Saim L, Saim S, et al. Prevalence of otitis media with effusion amongst pre-school children in Malaysia. Int J Pediatr Otorhinolaryngol 1997;41:21-8. https://doi.org/10.1016/s0165-5876(97)00049-9

22 Kitchens GG. Relationship of environmental tobacco smoke to otitis media in young children. Laryngoscope 1995;105:1-11.

23 Caylan R, Bektas D, Atalay C, et al. Prevalence and risk factors of otitis media with effusion in Trabzon, a city in northeastern Turkey, with an emphasis on the recommendation of OME screening. Eur Arch Otorhinolaryngol 2006;263:404-8. https://doi.org/10.1007/s00405-005-1023-1

24 Daly KA, Selvius RE, Lindgren B. Knowledge and attitudes about otitis media risk: implications for prevention. Pediatrics 1997;100:9316. https://doi.org/10.1542/peds.100.6.931

25 Padia R, Alt JA, Curtin K, et al. Environmental contributions to otitis media requiring tympanostomy tubes. Int J Pediatr Otorhinolaryngol 2017;101:97-101. https://doi.org/10.1016/j.ijporl.2017.07.035

26 Bugova G, Janickova M, Uhliarova B, et al. The effect of passive smoking on bacterial colonisation of the upper airways and selected laboratory parameters in children. Acta Otorhinolaryngol Ital 2018;38:431-8. https://doi.org/10.14639/0392-100X-1573 